\title{
Cocaine/crack use is not associated with fibrosis progression measured by AST-to- Platelet Ratio Index in HIV-HCV co-infected patients: a cohort study
}

Valérie Martel-Laferrière ${ }^{1 *}$, Roy Nitulescu' ${ }^{2}$, Joseph Cox ${ }^{2}$, Curtis Cooper ${ }^{3}$, Mark Tyndall ${ }^{4,5}$, Danielle Rouleau', Sharon Walmsley ${ }^{6}$, Leo Wong ${ }^{2}$, Marina B. Klein ${ }^{2^{*}}$ and for the Canadian Co-infection Cohort Study Investigators

\begin{abstract}
Background: Cocaine and crack use has been associated with HIV and HCV infections, but its consequences on HCV progression have not been well established. We analyzed the impact of cocaine/crack use on liver fibrosis progression in a cohort of HIV-HCV co-infected patients.

Methods: A Canadian multicenter prospective cohort study followed 1238 HIV-HCV co-infected persons every 6 months between 2003 and 2013. Data were analyzed from 573 patients with positive HCV RNA, not on HCV treatment, without significant liver fibrosis (AST-to-Platelet Ratio Index (APRI) $<1.5)$ or history of end-stage liver disease at baseline, and having at least two study visits. Recent cocaine/crack use was defined as use within 6 months of cohort entry. Incidence rates of progression to significant fibrosis (APRI $\geq 1.5$ ) were determined according to recent cocaine/crack use. Cox Proportional Hazards models were used to assess the association between time-updated cocaine/crack use and progression to APRI $\geq 1.5$ adjusting for age, sex, HCV duration, baseline In(APRI), and time-updated alcohol abuse, history of other drug use and CD4+ cell count.

Results: At baseline, 211 persons (37\%) were recent cocaine/crack users and 501 (87\%) ever used cocaine/ crack. Recent users did not differ from non-recent users on gender, age, and CD4+ T-cell count. Over 1599 person-years of follow up (522 PY in recent users, 887 PY in previous users and 190 PY in never users), 158 (28\%) persons developed significant fibrosis (9.9/100 PY; 95\% Cl, 8.3-11.4); 56 (27\%) recent users (10.7/100 PY; 7.9-13.5), 81 (28\%) previous users (9.1/100 PY; 7.1-11.1), and 21 (29\%) never users (11.1/100 PY; 6.3-15.8). There was no association between ever having used or time-updated cocaine/crack use and progression to $A P R I \geq 1.5$ (adjusted HR $(95 \% \mathrm{Cl}): 0.96(0.58,1.57)$ and $0.88 ;(0.63-1.25)$, respectively).
\end{abstract}

Conclusions: We could not find evidence that cocaine/crack use is associated with progression to advanced liver fibrosis in our prospective study of HIV-HCV co-infected patients.

Keywords: HIV, Cocaine, Liver fibrosis, APRI score

\footnotetext{
* Correspondence: valerie.martel-laferriere@umontreal.ca; marina.klein@mcgill.ca

'Centre de Recherche du Centre hospitalier de I'Université de Montréal, 900 Saint-Denis, Montréal, Quebec H2X 0A9, Canada

${ }^{2}$ McGill University Health Centre, 1001 Decarie Blvd, Montreal, Quebec H4A

3J1, Canada

Full list of author information is available at the end of the article
} 


\section{Background}

Worldwide, the number of cocaine/crack users is estimated at 14-21 million people, including 5.7 million North Americans [1]. Cocaine/crack addiction is a significant problem in Canada. In the Canadian Alcohol and Drug Use Monitoring Survey, cocaine use was reported by $0.9 \%$ of persons surveyed in 2011 [2]. In the I-track study published in 2010, cocaine was the most frequently injected drug, with $52 \%$ percent of injection drug users (IDU) reporting having used it in the last 6 months [3]. Similarly, in the SurvUDI network study (2003-2008), 86\% of IDU reported injecting cocaine and $68 \%$ reported smoking crack/freebase [4].

Cocaine/crack use has been associated with an increased risk of HIV and hepatitis $\mathrm{C}$ (HCV) transmission, even when the drug is not injected [5-7]. This phenomenon could result from mucous membrane lesions, sharing of material and at-risk sexual behaviours [8]. On the other hand, the impact of cocaine/ crack on the natural history and treatment of HIV and $\mathrm{HCV}$ is an understudied phenomenon. This situation is due, in part, to the absence of a substitute for cocaine as compared to methadone and buprenorphine for opiates [9]. Nevertheless, it is plausible that cocaine/crack could accelerate liver fibrosis progression through vascular damage and recurrent episodes of ischemic acute hepatitis.

The aim of our study is to determine if cocaine/crack use is associated with accelerated liver fibrosis progression among $\mathrm{HIV} / \mathrm{HCV}$ co-infected patients as measured by the APRI score.

\section{Methods}

\section{Participants}

The Canadian Co-Infection Cohort is an open prospective multi-centre cohort study of $\mathrm{HIV} / \mathrm{HCV}$ co-infected individuals $(n=1238)$ recruited from 18 centers across Canada since 2003. It represents approximately $20 \%$ of the co-infected population under care in Canada. Inclusion criteria are: $\geq 16$ year old, documented HIV infection by serological assay confirmed by Western blot, HCV infection documented by serological assay or, in case of false-negative serology, a positive HCV RNA. Socio-demographic and behavioral data are collected by self-reported questionnaires. Medical charts are reviewed for medical treatments and diagnoses and samples are collected at baseline and every 6 months. Details of the cohort can be found elsewhere [10].

Inclusion criteria for this analysis included participants with chronic $\mathrm{HCV}$ infection (positive HCV RNA), not receiving $\mathrm{HCV}$ treatment at baseline, who did not have significant liver fibrosis (see below) or a history of endstage liver disease at baseline and who had at least two study visits. Patients were followed until their first outcome occurrence, initiation of $\mathrm{HCV}$ treatment or last study visit before database closure in December 2013.

\section{Cocaine/crack use}

The exposure of interest was cocaine/crack use, either recent (within 6 months of a study visit), previous but not within 6 months, or never. Data concerning drug use were collected at every study visit. Questions evaluated types of drug used and routes of administration (injection vs. other) ever and in the last 6 months.

\section{Outcome: significant liver fibrosis}

The AST-to-Platelet Ratio (APRI; (AST/ULN)/platelets $\times 100)$ is a non-invasive scoring system allowing for categorization of patients as free of significant fibrosis (score $\leq 0.5$ ), with advanced fibrosis $(\geq 1.5)$ or with cirrhosis $(\geq 2)$. The main outcome of interest was occurrence of significant liver fibrosis defined as an $\mathrm{APRI} \geq 1.5[11]$

\section{Statistical analyses}

Descriptive statistics were used to characterize variables at baseline. Medians and interquartile ranges or numbers and proportions are reported for continuous and discrete variables respectively.

The following covariates of interest were measured: age, sex, ethnicity, income, body mass index (BMI), diabetes (determined based on glucose and fasting status), duration of HCV infection and time since HIV diagnosis and time updated HIV viral load and CD4+ cell count, antiretroviral therapy use, IDU, cocaine, crack and alcohol abuse in the previous 6 months. HCV duration was determined as time since first $\mathrm{HCV}$ diagnosis test, probable $\mathrm{HCV}$ infection according to patient, or first injection drug use, whichever was greater. Alcohol abuse was defined as more than six drinks at least once a month or more than two drinks on a typical day when drinking.

Incidence rates of progression to significant fibrosis $(A P R I \geq 1.5)$ from baseline (cohort entry) were determined according to recent cocaine/crack use. Cox Proportional Hazards models were used to assess the association between time-updated recent cocaine/crack use and progression to $\mathrm{APRI} \geq 1.5$, while adjusting for baseline age, sex, HCV duration, $\ln (\mathrm{APRI})$ and previous use of cocaine/crack at at any time prior the baseline visit and time-updated current alcohol abuse, use of other drugs, and CD4+ cell count. The final model was constructed using covariates selected $a$ priori as likely to be potential confounders. A sensitivity analysis was also performed by replicating the primary analysis using an APRI cut-off of 2 (cirrhosis) rather than 1.5. In case of missing variables, imputation rules were used. Indicator 
variables were imputed as false, continuous variables were imputed with their mean or median, depending on the shape of their distributions. All analyses were conducted using $\mathrm{R}$ version 3.3.0 ( $\mathrm{R}$ Core Team, 2016).

\section{Results}

A total of 573 patients met inclusion criteria of whom, at baseline, 211 persons (36.8\%) were recent cocaine/ crack users, 290 (50.6\%) persons previously used cocaine/crack but were not currently using, and 72 (12.6\%) persons never used cocaine/crack (Fig. 1 and Table 1). Over the course of follow up, $47 \%$ of previous users and $3 \%$ of never users became recent users, while $79 \%$ of recent users remained recent users.

Recent cocaine/crack users did not differ from previous users and never users on gender, age, and time since HIV diagnosis. At baseline, recent users were more likely to be be younger and of of Aboriginal origin, had lower CD4+ T-cells, were more likely to abuse alcohol, had longer median durations of $\mathrm{HCV}$ infection, but had lower median APRI scores and were more likely to be $\mathrm{HCV}$ treatment naive. The three groups did not differ with respect to reasons for censoring except that study withdrawal and $\mathrm{HCV}$ treatment initiations were more frequent among never users (Table 2).

Over 1599 person-years of follow up (522 PY in recent cocaine/crack users, $887 \mathrm{PY}$ in previous users, and 190 PY in never users), 158 (28\%) persons developed significant fibrosis (9.9/100 PY; 95\% CI, 8.3-11.4), of whom 56 (27\%) were recent users (10.7/100 PY; 7.9-13.5), 81 (28\%) were previous users (9.1/100 PY; 7.1-11.1), and 21 (29\%) were never users (11.1/100 PY; 6.3-15.8).

Because drug use can change over time, a model was built with time-updated status for recent cocaine/crack use and recent other drug use (Table 3). Time-updated recent cocaine/crack use and ever using cocaine/crack at baseline were not associated with progression to an APRI $\geq 1.5$ (recent: $0.88(0.63-1.25)$ and ever (0.96 $(0.58-1.57))$. Female sex, higher baseline $\ln ($ APRI), current alcohol abuse, and lower CD4 counts were significantly associated with the fibrosis progression.

Similarly, cocaine/crack use was not associated with progression to an APRI $\geq 2$ in both time-updated recent users and previous users at baseline (recent: $0.69(0.45-$ 1.04) and ever: $0.83(0.50-1.40))$ (Table 4). Female sex, higher baseline $\ln ($ APRI score), current alcohol abuse, and lower CD4 count were also associated with achieving and $\mathrm{APRI} \geq 2$.

\section{Discussion}

In this longitudinal study of liver fibrosis progression in HIV-HCV co-infected patients, we were unable to demonstrate an association between cocaine/crack use and evolution of liver fibrosis as measured by APRI score. Not surprisingly, alcohol abuse, CD4 cell count and baseline APRI score were predictors of progression to advanced fibrosis. The association between female sex and liver fibrosis progression although not generally seen in HCV mono-infection was previously noted in the Canadian Co-infection cohort and other co-infected studies [12, 13].

The influence of cocaine on liver pathology has been studied in animal models. Cocaine has been associated with parenchymal necrosis and microvesicular changes in hepatic architecture [14]. Cocaine is metabolised in the liver by CYP450 to norcocaine [15]. Norcocaine is then transformed into free radicals which cause liver damage [14]. Decreased ATPase activity in isolated rat liver mitochondria was also reported [16]. In addition, liver damage can result from damage to other organs through hyperpyrexia, hypotension and rhabdomyolysis $[15,17]$.

With respect to fibrosis and liver function, data from clinical human studies are currently limited. In a retrospective study, transplant recipients who received a liver from a donor who was a cocaine user had higher levels of prothrombin time and AST on post-operative day one and more graft loss within 3 months as compared to recipients of livers from noncocaine users [14]. There was also more primary nonfunction and lower graft survival in the cocaine group. One potential confounder in this study was that cocaine users were also more likely to drink alcohol. Nevertheless, the study suggests at least a subclinical impact of cocaine on liver function [14].

On the other hand, Foucher et al. study contradicts the hypothesis of accelerated liver disease progression among cocaine users [18]. Cocaine-snorting was not associated with elevated transient elastography scores in their study performed on 298 drug users. However, those who never snorted cocaine and had less than 21 drinks per week were more likely to be $\mathrm{HCV}$ seropositive raising concerns about the generalizability of these findings [18]. Multiple other studies have shown a high correlation between cocaine use and HCV infection, [19, 20] although none has investigated the effect of cocaine on liver disease progression.

Our study is the first to evaluate systematically the presence of an association between cocaine/crack use and liver fibrosis. This was done in a large prospective cohort of HIV-HCV co-infected patients, representative of the population of co-infected patients in care in Canada. We controlled for major known confounders that could be linked with cocaine use and liver disease risk. 


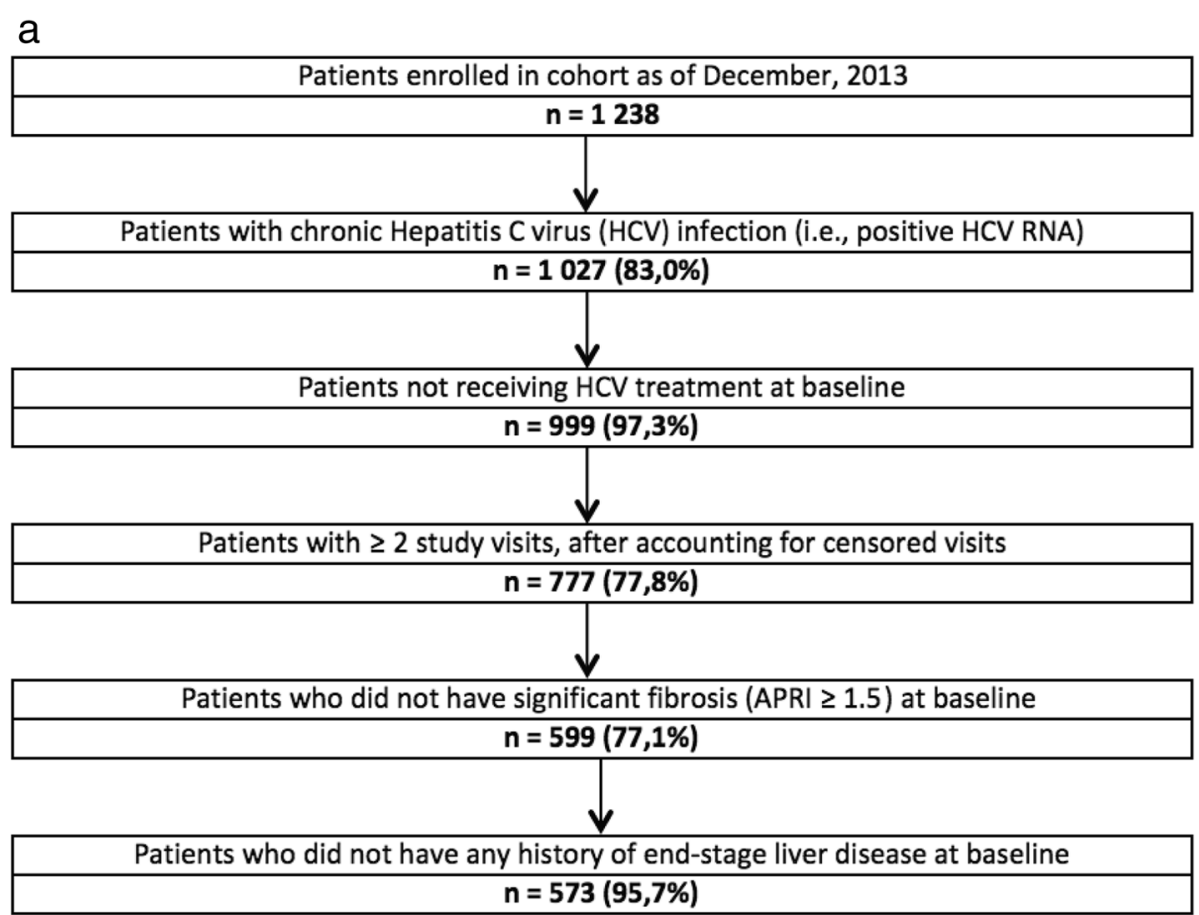

b

\begin{tabular}{|c|c|c|}
\hline \multicolumn{3}{|c|}{ Patients enrolled in cohort as of December, 2013} \\
\hline Recent cc use & Ever used $\mathrm{cc}$ & Never used cc \\
\hline$n=432$ & $n=622$ & $n=184$ \\
\hline \multicolumn{3}{|c|}{$\downarrow$} \\
\hline \multicolumn{3}{|c|}{ Patients with chronic Hepatitis C virus (HCV) infection (i.e., positive HCV RNA) } \\
\hline Recent cc use & Ever used cc & Never used cc \\
\hline $\mathrm{n}=354(81,9 \%)$ & $n=526(84,6 \%)$ & $n=147(79,9 \%)$ \\
\hline \multicolumn{3}{|c|}{$\downarrow$} \\
\hline \multicolumn{3}{|c|}{ Patients not receiving HCV treatment at baseline } \\
\hline Recent cc use & Ever used cc & Never used cc \\
\hline $\mathrm{n}=350(98,9 \%)$ & $n=508(96,6 \%)$ & $\mathrm{n}=141(95,9 \%)$ \\
\hline \multicolumn{3}{|c|}{$\downarrow$} \\
\hline \multicolumn{3}{|c|}{ Patients with $\geq 2$ study visits, after accounting for censored visits } \\
\hline Recent cc use & \multirow{2}{*}{$\begin{array}{c}\text { Ever used cc } \\
\mathbf{n}=\mathbf{3 9 8}(\mathbf{7 8 , 3} \%)\end{array}$} & Never used cc \\
\hline $\mathrm{n}=\mathbf{2 7 2}(\mathbf{7 7 , 7 \% )}$ & & $\mathrm{n}=107(75,9 \%)$ \\
\hline \multicolumn{3}{|c|}{$\downarrow$} \\
\hline \multicolumn{3}{|c|}{ Patients who did not have significant fibrosis (APRI $\geq 1.5$ ) at baseline } \\
\hline Recent cc use & \multirow{2}{*}{$\begin{array}{c}\text { Ever used cc } \\
\mathbf{n}=\mathbf{3 0 3}(\mathbf{7 6 , 1 \% )}\end{array}$} & Never used cc \\
\hline $\mathrm{n}=\mathbf{2 2 1}(\mathbf{8 1 , 2 \% )}$ & & $\mathrm{n}=75(70,1 \%)$ \\
\hline \\
\hline \multicolumn{3}{|c|}{ Patients who did not have any history of end-stage liver disease at baseline } \\
\hline Recent cc use & Ever used cc & Never used cc \\
\hline $\mathrm{n}=211(95,5 \%)$ & $\mathbf{n}=\mathbf{2 9 0}(95,7 \%)$ & $\mathrm{n}=72(96,0 \%)$ \\
\hline
\end{tabular}

Fig. 1 a Sample Selection Flow Chart. b Sample Selection Flow Chart Stratified by Group Legend: cc: Cocaine/crack 
Table 1 Baseline characteristics of study population

\begin{tabular}{lllll}
\hline & Total $(N=573)$ & $\begin{array}{l}\text { Recent cocaine/crack } \\
\text { use }(N=211)\end{array}$ & $\begin{array}{l}\text { Previously used cocaine/crack; } \\
\text { not recent }(N=290)\end{array}$ & $\begin{array}{l}\text { Never used cocaine/ } \\
\text { crack (N=72) }\end{array}$ \\
\hline Follow-up time (years) $)^{\text {a }}$ & $2.3(1.0,4.1)$ & $2.1(1.0,3.9)$ & $2.4(1.1,4.5)$ & $2.0(0.8,4.4)$ \\
Age (years) & $44(38,49)$ & $43(38,49)$ & $44(38,48)$ & $47(40,53)$ \\
Female & $173(30 \%)$ & $69(33 \%)$ & $81(28 \%)$ & $23(32 \%)$ \\
Aboriginal & $86(15 \%)$ & $53(25 \%)$ & $31(11 \%)$ & $2(3 \%)$ \\
Time since HIV diagnosis (years) & $10(5,16)$ & $10(5,14)$ & $10(6,16)$ & $13(5,20)$ \\
Duration HCV infection (years) & $18(10,25)$ & $19(12,26)$ & $18(11,25)$ & $10(4,20)$ \\
CD4 cell count (cells/mL) & $389(253,550)$ & $360(220,528)$ & $390(260,550)$ & $439(300,601)$ \\
HIV RNA load $\leq 50$ copies/mL & $340(59 \%)$ & $117(55 \%)$ & $175(60 \%)$ & $48(67 \%)$ \\
Time since first start of ART (years) & $6(2,11)$ & $6(2,10)$ & $6(3,11)$ & $9(2,12)$ \\
CART regimen & $453(79 \%)$ & $164(78 \%)$ & $227(78 \%)$ & $62(86 \%)$ \\
Prior AIDS diagnosis & $162(28 \%)$ & $65(31 \%)$ & $77(27 \%)$ & $20(28 \%)$ \\
APRI & $0.5(0.4,0.8)$ & $0.5(0.4,0.7)$ & $0.6(0.4,0.8)$ & $0.6(0.4,1.0)$ \\
HCV RNA (logio Ul/mL) & $6.2(5.4,6.7)$ & $6.1(5.1,6.6)$ & $6.2(5.5,6.8)$ & $6.2(5.6,6.7)$ \\
HCV treatment naïve & $512(89 \%)$ & $197(93 \%)$ & $258(89 \%)$ & $57(79 \%)$ \\
Alcohol abuse & $83(14 \%)$ & $41(19 \%)$ & $37(13 \%)$ & $5(7 \%)$
\end{tabular}

a: Median (IQR) or Number (\%)

b: For HCV RNA only 307 (86/211 (41\%) recent cocaine/crack users, 170/290 (59\%) previous/not recent cocaine/crack users, and 51/72 (71\%) non cocaine/crack users) had available quantitative HCV RNA values

c: Defined as $>6$ drinks at least once a month and $>2$ drinks on a typical day when drinking

Among study limitations, the most important is that data about quantity and route of administration other than injection are not collected in our study questionnaire. Consequently, we cannot exclude a dose-related effect of cocaine/crack on liver fibrosis. Concerning route of administration, we chose to combine all routes of administration together based on previous studies showing that similar serum concentrations are achieved when these drugs are injected and smoked although some studies suggest snorted cocaine leads to lower plasma drug concentration [21]. Because almost the entire patient population $(87 \%)$ had used cocaine or crack at some time, focusing only on recent use could miss potential long-term effects of cocaine on the liver. In order to account for consumption changes over time, we used a time-updated variable

Table 2 Reasons for censoring

\begin{tabular}{llll}
\hline & $\begin{array}{l}\text { Recent cocaine/ } \\
\text { crack use } \\
n=211\end{array}$ & $\begin{array}{l}\text { Previously used } \\
\text { cocaine/crack } \\
n=290\end{array}$ & $\begin{array}{l}\text { Never used } \\
\text { cocaine/crack } \\
n=72\end{array}$ \\
\hline $\begin{array}{l}\text { Outcome (APRI } \geq 1.5) \\
\text { End of study period }\end{array}$ & $99(47 \%)$ & $81(28 \%)$ & $21(29 \%)$ \\
$\begin{array}{l}\text { HCV Treatment } \\
\text { initiation }\end{array}$ & $15(7 \%)$ & $37(33 \%)$ & $21(29 \%)$ \\
Death & $11(5 \%)$ & $24(8 \%)$ & $13(18 \%)$ \\
Lost to follow-up & $23(11 \%)$ & $33(11 \%)$ & $7(10 \%)$ \\
Withdrawal & $7(3 \%)$ & $19(7 \%)$ & $8(11 \%)$ \\
\hline
\end{tabular}

for recent cocaine/crack use. However, we did not have a measure of duration or intensity of such drug use prior to cohort entry.

Arguably APRI score is an imperfect surrogate for liver fibrosis and is not the gold standard for liver fibrosis evaluation. Nevertheless, because of cost and potential safety risks, it is not possible to perform

Table 3 Multivariate analysis of cocaine/crack use and liver fibrosis progression

\begin{tabular}{|c|c|c|}
\hline & \multicolumn{2}{|c|}{$\begin{array}{l}\text { Recent cocaine/ } \\
\text { crack use }\end{array}$} \\
\hline & $\mathrm{HR}$ & $95 \% \mathrm{Cl}$ \\
\hline \multicolumn{3}{|l|}{ Time independent variables (at baseline) } \\
\hline Cocaine/crack use ever at baseline & 0.96 & $0.58,1.57$ \\
\hline Baseline age (per 10 years) & 1.04 & $0.86,1.27$ \\
\hline Female sex & 1.45 & $1.04,2.01$ \\
\hline Baseline HCV infection duration (per 5 years) & 1.00 & $0.92,1.10$ \\
\hline Baseline In (APRI) & 2.84 & $1.94,4.16$ \\
\hline \multicolumn{3}{|l|}{ Time updated variables } \\
\hline Recent cocaine/crack use & 0.88 & $0.63,1.25$ \\
\hline Recent other drug use $\mathrm{a}^{\mathrm{a}}$ & 1.07 & $0.77,1.49$ \\
\hline Current alcohol abuse $^{\mathrm{b}}$ & 1.63 & $1.09,2.42$ \\
\hline 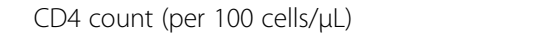 & 0.90 & $0.84,0.96$ \\
\hline
\end{tabular}

${ }^{a}$ Heroin and opiates, steroids, methylphenidate, hallucinogens (PCP, LSD), benzodiazepine, barbiturates, methamphetamine, amphetamine, other ${ }^{b}$ Defined as $>6$ drinks at least once a month and $>2$ drinks on a typical day when drinking 
Table 4 Multivariate analysis of cocaine/crack use and liver fibrosis progression using cut-off of 2 for APRI

\begin{tabular}{lll}
\hline & \multicolumn{2}{l}{$\begin{array}{l}\text { Recent cocaine/ } \\
\text { crack use }\end{array}$} \\
\cline { 2 - 3 } & HR & $95 \% \mathrm{Cl}$ \\
\hline Time independent variables (at baseline) & & \\
Cocaine/crack use ever at baseline & 0.83 & $0.50,1.40$ \\
Baseline age (per 10 years) & 1.04 & $0.83,1.29$ \\
Female sex & 1.48 & $1.03,2.13$ \\
Baseline HCV infection duration (per 5 years) & 1.05 & $0.95,1.16$ \\
Baseline In (APRI) & 2.54 & $1.69,3.81$ \\
Time updated variables & & \\
Recent cocaine/crack use & 0.69 & $0.45,1.04$ \\
Recent other drug use ${ }^{\mathrm{a}}$ & 1.19 & $0.82,1.72$ \\
Current alcohol abuse ${ }^{\mathrm{b}}$ & 1.76 & $1.14,2.72$ \\
CD4 count (per 100 cells/ $\mu \mathrm{L}$ ) & 0.91 & $0.85,0.98$ \\
\hline
\end{tabular}

${ }^{a}$ Heroin and opiates, steroids, methylphenidate, hallucinogens (PCP, LSD), benzodiazepine, barbiturates, methamphetamine, amphetamine, other ${ }^{\mathrm{b}}$ Defined as $>6$ drinks at least once a month and $>2$ drinks on a typical day when drinking

repetitive liver biopsy in a cohort study. In addition, even if transient elastography is now considered as a validated non-invasive test for liver fibrosis and is well suited for repeated testing, it was not available when the cohort was formed and is still not available to all our study sites. APRI is widely used in clinical practice and has been recommended by the World Health Organization [22]. Despite a meta-analysis showing a trend toward less accurate results for APRI in co-infected than mono-infected patients, this difference was not significant in meta-regression analysis and APRI has been validated in our $\mathrm{HIV} / \mathrm{HCV}$ coinfected patients $[11,23]$. Multiple studies have used the APRI score and demonstrated its value in predicting liver fibrosis progression, hepatic decompensation and death [11, 24-27]. The APRI score has been shown to perform similarly to other markers of liver fibrosis including FIB-4 [28]. The APRI score lacks sensitivity and may misclassify individuals as not having fibrosis, however is highly specific for fibrosis stage $\geq$ F2 (0.93, 95\% CI: 0.91, 0.94) [23]. Thus using APRI $\geq 1.5$ as an outcome is conservative. While we may have underestimated the degree of fibrosis present among those with scores below 1.5, any such under-ascertainment is unlikely to vary by exposure to cocaine. Nevertheless, because there is some controversy concerning the clinical significance of progression to an APRI $\geq 1.5$, we conducted a sensitivity analysis with an APRI cut-off value of 2, corresponding to liver cirrhosis. Similar to the other models, recent cocaine/crack use or ever using cocaine/crack was not associated with APRI progression.

\section{Conclusions}

In conclusion, while cocaine/crack use is certainly associated with high-risk behaviours related to $\mathrm{HCV}$ infection and to potential acute liver injury, we were unable to demonstrate an association between these drugs and chronic liver fibrosis progression.

\section{Abbreviations \\ APRI: AST-to-Platelet Ratio; BMI: Body mass index; HCV: Hepatitis C; IDU: Injection drug users; PY: Person-years}

\section{Acknowledgments}

We thank all the study participants, study coordinators and nurses for their assistance with study coordination, participant recruitment and care. The Canadian Co-infection cohort investigators (CTN222) are: Drs. Lisa Barrett QEll Health Science Center for Clinical Research, Halifax, NS; Jeff Cohen, Windsor Regional Hospital Metropolitan Campus, Windsor, ON; Brian Conway, Vancouver Infectious Diseases Research and Care Centre, Vancouver, BC; Curtis Cooper, The Ottawa Hospital Research Institute, Ottawa ON; Pierre Côté, Clinique du Quartier Latin, Montréal, QC; Joseph Cox, MUHC IDTCMontréal General Hospital, Montréal, QC; John Gill, Southern Alberta HIV Clinic, Calgary, AB; Shariq Haider, McMaster University, Hamilton, ON; Mark Hull, BC Centre for Excellence in HIV/AIDS, Vancouver, BC; Marina Klein, McGill University Health Centre, Division of Infectious Diseases and Chronic Viral Illness Service, Montreal, QC; Julio Montaner, St. Paul's Hospital, Vancouver, BC; Erica Moodie, McGill University, Montreal, QC; Neora Pick, Oak Tree Clinic, Children's and Women's Health Centre of British Columbia, University of British Columbia, Vancouver, BC; Anita Rachlis, Sunnybrook \& Women's College Health Sciences Centre, Toronto, ON; Danielle Rouleau, Centre Hospitalier de I'Université de Montréal, Montréal, QC; Roger Sandre, HAVEN Program, Sudbury, ON; Mark Tyndall, Department of Medicine, Infectious Diseases Division, University of Ottawa, Ottawa ON; Steve Sanche, SHARE University of Saskatchewan, Saskatoon, SK; Marie-Louise Vachon, Centre Hospitalier Universitaire de Québec, Québec, QC; Sharon Walmsley, University Health Network, Toronto, ON; Alex Wong, Regina Qu'Appelle Health Region, Regina General Hospital, Regina, SK.; and David Wong, University Health Network, Toronto, ON.

\section{Funding}

This work was supported through grant support from the Fonds de recherche en santé- Quebec, Réseau SIDA/maladies infectieuses (FRQ-S); the Canadian Institutes of Health Research (CIHR MOP-79529); the Canadian Institutes of Health Research Canadian HIV Trials Network (CTN222). Valérie Martel-Laferrière received a Travel Awards - Institute Community Support from the Canadian Institute for Health Research for this work. Sharon Walmsley is supported by a career scientist award from the Ontario HIV Treatment Network. Marina Klein is supported by the "Chercheurs Nationaux" career award from the FRQ-S

\section{Availability of data and materials}

According to stipulations of the patient consent form signed by all study participants, ethical restrictions imposed by our Institutional Ethics review boards, and legal restrictions imposed by Canadian law regarding clinical trials, anonymized data are available upon request by contacting Dr. Marina Klein.

\section{Authors' contributions}

VML: study protocol development, collection of data, data analysis, manuscript writing. RN: data analysis, critical revision of the manuscript. JC: study protocol development, collection of data, critical revision of the manuscript. CC: study protocol development, collection of data, critical revision of the manuscript. MT: study protocol development, collection of data, critical revision of the manuscript. DR: study protocol development, collection of data, critical revision of the manuscript. SW: study protocol development, collection of data, critical revision of the manuscript. LW: data analysis, critical revision of the manuscript. MBK: study protocol development, collection of data, data analysis, critical revision of the manuscript. All authors read and approved the final manuscript. 


\section{Competing interests}

V. Martel- Laferrière reports consulting fees from Merck and Gilead, grant from Gilead and lecture fees from AbbVie, Merck and Gilead. J. Cox reports consulting fees from Gilead and grants from AbbVie and Merck. C. Cooper reports non-financial support from Bristol-Myers Squibb, Gilead, Merck and AbbVie. M. Tyndall reports receipt of grants from Gilead, BMS, Janssen and previous honoraria for lectures from Gilead. D. Rouleau reports grants from Merck. S.Walmsley reports grants, consulting fees and lecture fees from Merck, Abbvie, ViiV Healthcare, Gilead, and Bristol-Myers Squibb. M.B. Klein reports grants from ViiV Healthcare and Merck; and consulting fees from ViiV Healthcare, Bristol-Myers Squibb, Gliead, Merck and Abbvie. L. Wong, and R. Nitulescu, report no conflicts of interest.

\section{Consent for publication}

Not applicable.

\section{Ethics approval and consent to participate}

Ethics committee approval was obtained from all study sites. Individual written informed consent was obtained from all participants before enrolment. The CCC was approved by the community advisory committee of the CIHR-Canadian HIV Trials Network, the Biomedical B Research Ethics Board of the McGill University Health Centre (site: Chronic Viral Illness Service - McGill University Health Centre), the Institutional Review Board Services (site: Vancouver Infectious Diseases Centre), the Conjoint Health Research Ethics Board at the University of Calgary (site: Southern Alberta Clinic), the Windsor Regional Hospital Research Ethics Board (site: Windsor Regional Hospital - Metropolitan Campus), Veritas Independent Review Board (site: Clinique Médicale du Quartier-Latin), the Hamilton Integrated Research Ethics Board (site: MacMaster University Medical Centre Hamilton Health Sciences) the Comité d'éthique de la recherche du Centre hospitalier de I'Université de Montréal (site: Centre hospitalier de l'Université de Montréal), the Comité d'éthique de la recherche du CHU de Québec (CHU de Québec - CHUL Quebec city), the Sunnybrook Health Sciences Centre Research Ethics Board (site: Sunnybrook Health Sciences Center), the Research Ethics Board of Health Sciences North (site: Heath Science North - The HAVEN Program), the University Health Network Research Ethics Board (site: University Health Network - Toronto General Hospital), the UBC-Providence Health Care Research Ethics Board (sites: Oak Tree Clinic, BC Centre For Excellence in HIV/AIDS, Native BC Health Center - St-Paul's Hospital), the Regina Qu'Appelle Health Region (RQHR) Research Ethics Board (site: Regina Qu'Appelle Health Region - Regina General Hospital), the Nova Scotia Health Research Ethics Board (site: QUEII Health Science Center), the Biomedical Research Ethics Board (Bio-REB) (site: SHARE University of Saskatchewan Saskatoon), and the Ottawa Health Science Network Research Ethics Board (site: The Ottawa Hospital - General Campus)

\section{Author details}

${ }^{1}$ Centre de Recherche du Centre hospitalier de I'Université de Montréal, 900 Saint-Denis, Montréal, Quebec H2X 0A9, Canada. ${ }^{2}$ McGill University Health Centre, 1001 Decarie Blvd, Montreal, Quebec H4A 3J1, Canada. ${ }^{3}$ Ottawa Hospital Research Institute, 501 Smyth Rd, Ottawa, Ontario K1H 8L6, Canada. ${ }^{4}$ University of British Columbia, 2775 Laurel Street, 10th Floor, Vancouver, British Columbia V5Z 1M9, Canada. ${ }^{5}$ B.C. Centre for Disease Control (BCCDC), 655 W 12th Ave, Vancouver, BC V5Z 4R4, Canada. ' University Health Network, 101 College, Toronto, Ontario M5G 1L7, Canada.

Received: 10 June 2016 Accepted: 6 January 2017

Published online: 17 January 2017

\section{References}

1. Pomara C, Cassano T, D'Errico S, Bello S, Romano AD, Riezzo I, et al. Data available on the extent of cocaine use and dependence: biochemistry, pharmacologic effects and global burden of disease of cocaine abusers. Curr Med Chem. 2012;19(33):5647-57.

2. Health Canada. Canadian Alcohol and Drug Use Monitoring Survey 2011 [cited 2013 November 10]. Available from: http://www.hc-sc.gc.ca/hc-ps/ drugs-drogues/stat/_2011/summary-sommaire-eng.php.

3. Public Health Agency of Canada. Chapitre 10: Le VIH/sida chez les utilisateurs drogues injectables au Canada 2010 [cited 2013 November 10]. Available from: http://www.phac-aspc.gc.ca/aids-sida/publication/epi/2010/ 10-fra.php.
4. Institut de Santé Publique du Québec. Surveillance des maladies infectieuses chez les utilisateurs de drogues par injection 2009. 2009. [cited 2013 November 10]. Available from: http://www.inspq.qc.ca/pdf/ publications/1021_SurvMallnfecUDI_VIHVHC2008.pdf.

5. Nurutdinova D, Abdallah AB, Bradford S, O'Leary CC, Cottler LB. Risk factors associated with Hepatitis $C$ among female substance users enrolled in community-based HIV prevention studies. BMC Res Notes. 2011;4:126. Pubmed Central PMCID: 3095996.

6. Burton MJ, Olivier J, Mena L. Characteristics of hepatitis C virus coinfection in a human immunodeficiency virus-infected population with lower reported rates of injection drug use. Am J Med Sci. 2009;338(1):54-6.

7. Macias J, Palacios RB, Claro E, Vargas J, Vergara S, Mira JA, et al. High prevalence of hepatitis $C$ virus infection among noninjecting drug users: association with sharing the inhalation implements of crack. Liver Int. 2008; 28(6):781-6.

8. Leonard L, DeRubeis E, Pelude L, Medd E, Birkett N, Seto J. "I inject less as I have easier access to pipes": injecting, and sharing of crack-smoking materials, decline as safer crack-smoking resources are distributed. Int J Drug Policy. 2008;19(3):255-64.

9. Charlebois A, Lee L, Cooper E, Mason K, Powis J. Factors associated with HCV antiviral treatment uptake among participants of a community-based HCV programme for marginalized patients. J Viral Hepat. 2012;19(12):836-42.

10. Klein MB, Saeed S, Yang H, Cohen J, Conway B, Cooper C, et al. Cohort profile: the Canadian HIV-hepatitis C co-infection cohort study. Int J Epidemiol. 2010;39(5):1162-9.

11. Al-Mohri H, Cooper C, Murphy T, Klein MB. Validation of a simple model for predicting liver fibrosis in HIV/hepatitis C virus-coinfected patients. HIV Med. 2005:6(6):375-8.

12. Rollet-Kurhajec KC, Moodie EE, Walmsley S, Cooper C, Pick N, Klein MB, et al. Hepatic Fibrosis Progression in HIV-Hepatitis C Virus Co-InfectionThe Effect of Sex on Risk of Significant Fibrosis Measured by Aspartateto-Platelet Ratio Index. PLoS One. 2015;10(6):e0129868. Pubmed Central PMCID: 4474689.

13. Mehta SH, Thomas DL, Torbenson M, Brinkley S, Mirel L, Chaisson RE, et al. The effect of antiretroviral therapy on liver disease among adults with HIV and hepatitis C coinfection. Hepatology. 2005;41(1):123-31.

14. Komokata T, Nishida S, Ganz S, Levi DM, Fukumori T, Tzakis AG. The impact of donor cocaine use on the outcome of adult liver transplantation. Clin Transpl. 2006;20(3):295-300.

15. Pateria $P$, de Boer B, Macquillan G. Liver abnormalities in drug and substance abusers. Best Pract Res Clin Gastroenterol. 2013;27(4):577-96.

16. Cunha-Oliveira T, Silva L, Silva AM, Moreno AJ, Oliveira CR, Santos MS. Acute effects of cocaine, morphine and their combination on bioenergetic function and susceptibility to oxidative stress of rat liver mitochondria. Life Sci. 2013;92(24-26):1157-64.

17. Silva MO, Roth D, Reddy KR, Fernandez JA, Albores-Saavedra J, Schiff ER. Hepatic dysfunction accompanying acute cocaine intoxication. J Hepatol. 1991;12(3):312-5.

18. Foucher J, Reiller B, Jullien V, Leal F, di Cesare ES, Merrouche W, et al. FibroScan used in street-based outreach for drug users is useful for hepatitis C virus screening and management: a prospective study. J Viral Hepat. 2009; 16(2):121-31.

19. Roux P, Fugon L, Jones JD, Comer SD. Hepatitis C infection in nontreatment-seeking heroin users: the burden of cocaine injection. Am J Addict/Am Acad Psychiatr Alcohol Addictions. 2013;22(6):613-8. Pubmed Central PMCID: 4059002.

20. Roy E, Alary M, Morissette C, Leclerc P, Boudreau JF, Parent R, et al. High hepatitis $C$ virus prevalence and incidence among Canadian intravenous drug users. Int J STD AIDS. 2007;18(1):23-7.

21. Evans SM, Cone EJ, Henningfield JE. Arterial and venous cocaine plasma concentrations in humans: relationship to route of administration, cardiovascular effects and subjective effects. J Pharmacol Exp Ther. 1996; 279(3):1345-56.

22. World Health Organization. Guidelines for the screening care and treatment of persons with chronic hepatitis C infection. Updated version, April 2016 [August 29th, 2016]. Available from: http://apps.who.int/iris/bitstream/10665/ 205035/1/9789241549615_eng.pdf?ua=1.

23. Lin ZH, Xin YN, Dong QJ, Wang Q, Jiang XJ, Zhan SH, et al. Performance of the aspartate aminotransferase-to-platelet ratio index for the staging of hepatitis C-related fibrosis: an updated meta-analysis. Hepatology. 2011; 53(3):726-36. 
24. Al-Mohri H, Murphy T, Lu Y, Lalonde RG, Klein MB. Evaluating liver fibrosis progression and the impact of antiretroviral therapy in HIV and hepatitis $C$ coinfection using a noninvasive marker. J Acquir Immune Defic Syndr. 2007; 44(4):463-9.

25. Thorpe J, Saeed S, Moodie EE, Klein MB. Canadian Co-infection Cohort S. Antiretroviral treatment interruption leads to progression of liver fibrosis in HIV-hepatitis C virus co-infection. Aids. 2011;25(7):967-75.

26. Bambha K, Pierce C, Cox C, French AL, Tien PC, Sharp GB, et al. Assessing mortality in women with hepatitis $C$ virus and HIV using indirect markers of fibrosis. Aids. 2012;26(5):599-607. Pubmed Central PMCID: 3698040.

27. Rohrbach J, Stickel F, Schmid P, Thormann W, Kovari H, Scherrer A, et al. Changes in biomarkers of liver disease during successful combination antiretroviral therapy in HIV-HCV-coinfected individuals. Antivir Ther. 2014; 19(2):149-59.

28. Nunes D, Fleming C, Offner G, O'Brien M, Tumilty S, Fix O, et al. HIV infection does not affect the performance of noninvasive markers of fibrosis for the diagnosis of hepatitis C virus-related liver disease. J Acquir Immune Defic Syndr. 2005;40(5):538-44.

Submit your next manuscript to BioMed Central and we will help you at every step:

- We accept pre-submission inquiries

- Our selector tool helps you to find the most relevant journal

- We provide round the clock customer support

- Convenient online submission

- Thorough peer review

- Inclusion in PubMed and all major indexing services

- Maximum visibility for your research

Submit your manuscript at www.biomedcentral.com/submit
Biomed Central 